\title{
Impact of Education on Social Mobility among Residents in Ilorin Metropolis (pp. 373-387)
}

Yusuf, Noah - Department of Sociology, University of Ilorin, Nigeria. noahsarkplc@yahoo.com +2348033831876; +2348078054426.

\begin{abstract}
In many societies of the world today, educational attainment is one of the most important factors determining the occupational and income level to which a person can aspire. This fact becomes more relevant in Nigeria in view of the rapid expansion of educational facilities in the country since the past three decades. Although on the whole, the illiteracy level in the country is low, education is still very important in determining a number of social chances of people in the Nigerian society. The study examined this important issue - the impact of education on social mobility in the Nigerian society, with particular emphasis on residents in Ilorin, Kwara State. It found that on the average, an individual's educational attainment tend to determine his occupational choice, income level and life style. The study found that respondents' educational attainment was not associated with fathers' educational level. On the other hand, close relationship were found between respondents' educational level and their income as well as social status.
\end{abstract}

Key Words: Education; Income; Occupation; Social Mobility; Society

\section{Introduction}

Most adolescents in contemporary society spend a greater part of their lives in institutions where they receive formal education. This form of education (formal) is regarded as a major agency of socialization in these societies (Bilton, et. al. 1989; Giddens and Duneier, 2000). However, socialization is continuous process in which individuals are subjected to its influence before, alongside and after their school career. Education is nevertheless considered 
as different from other forms of socialization in that it involves instruction which is deliberate and conducted within formal organization set aside for that purpose and relatively standardized.

In its broadest sense, education is simply one aspect of socialization involving the acquisition of knowledge and the learning of skills. Formal education is a characteristic feature of modern societies. In traditional, small scale, non-literate societies, education is not distinguishable from other aspects of life. Rather, knowledge and skills are acquired informally by imitating examples provided by adults. In these societies, adults are responsible for instructing the younger ones as part of their daily routine. For instance, boys accompanied their fathers on hunting trips while girls assisted their mothers with cooking and gathering vegetables (Haralambos and Holborn, 2000). On the other hand, in more complex pre-industrial societies, specialized educational institutions are responsible for performing these roles.

In its broad sense, education embraces all those experiences of the individuals through which knowledge is acquired, the intellect enlightened or the will strengthened. In its strict sense, education designates the consciously planned and systematically acquired formal education or training carried on through the various social agencies of education especially the school (Marsh, 1997).

Essentially, education is necessary for preparing children for adult life in terms of diplomas and degrees to determine one's credentials also for a job even if the work involved has nothing to do with the education one has acquired. Education is also important in terms of certification (regarded as eligible for particular position) and socialization (meant to prepare individuals for adult role). In contemporary Nigerian society, education is regarded as a basic yardstick for the placement of people into important social positions.

Education is required for several reasons. These include acquiring knowledge, preparing individuals for various social roles, status, transmitting culture, to escape from dull and unpleasant occupation, source of knowledge, skill, which enables people to begin new tasks and do old ones more effectively and lastly to supply the manpower need of the country (Schaefer, 1989). 
Sociologists have debated why formal education developed in modern societies by focusing on the social functions that it provides. For example, some have emphasized the important role of education in socializing the individual to fit into, and perpetuate the social system. Education is here seen as serving the function of passing the collective consciousness and culture, of a pre-existing society (Marsh, 1997).

Social mobility refers to the amount of movement from one stratum to another. It describes the nature and amount of change in social position over time. In principle, this change can be defined foe any social entity. For instance, one can consider the collective mobility of classes, ethnic groups, or the entire nation in terms of health status, literacy and education. According to Haralambos and Horborn (2000) social mobility is significantly higher in industrial societies than in pre-industrial ones. In particular, status in preindustrial societies is largely ascribed. Consequently, ascribed characteristics i.e. class of origins, sex, race and kinship relations have less and less influence on individual's social status.. Rather, status is seen to be increasingly achieved on the basis of merit - talent, ability, ambition and hard work have replaced ascribed characteristics as the criteria for determining a person's position in the class system. It is in this respect that Pareson (1964) argued that achievement is one of the major values of most modern societies. Individuals are judged and accorded prestige in terms of their occupational status which is seen to be largely achieved by their own efforts and ability. Education has been considered as one of the instrument for attaining such achievement.

In most modern society today, education has become the key element in the process of social mobility. Educational qualification and the number of years completed at schools have become the most important yardstick needed for occupational attainment. The close association between years of schooling and level of occupational attainment and income is true of both developed and developing societies alike.

Occupational attainment and entry into elite post in the society seems to be dependent more than anything else on credentials. Imoagene (1976) in his study of western Nigerian new elite found that the difference in the occupational distribution in the father's generation is not significant. $\mathrm{He}$ argued that the factor for high occupation in the society i.e top civil servants, 
businessmen or Professors cannot be understood by referring to his origin status. Rather, education was the important single clue to understanding the career patterns and opportunity of the new elite. In other words, the type of first job taken on entry into workforce which is based on credentials determined a man's subsequent career.

However access to this important institution in the society is not evenly distributed among people. Rather, while some individuals have access to educational opportunity others find it difficult to acquire knowledge through this formalized method of learning.

Inequality in educational oppoirtunity has far reaching consequences on individuals, groups as well as the society as a whole. This is more so in developing societies where educational credentials more than anything else, determines a man's life chances (Imoagene, 1990). Thus, those who have the opportunity to education tend to acquire certain priviledges that can be illafforded by others who lack this basic training.

Education, no doubt is an important instrument of change in modern societies. With education an individual or group can rise towards more highly valued positions and rewards in society. According to Akerejola (1977) knowledge of the mobility function of education may be the major motivating force for sending children to school. To these children in turn, educational success means fulfilled life.

Bilton and his group (1989) argued that until the Second World War, education (especially in Britain) had limited impact as a vehicle of social mobility. They further contended that the educational system then did not provide a ladder for social mobility. Rather, it was the stamp put in the social character of individuals whose jobs and lifestyle were pre-determined by social origin.

However, it is recognized that in every society a particular system of social mobility exists, though in variety of forms. For instance, Imoagene (1976) contends that largely due to the disruption in the traditional way of life which has led to change in the importance of different status positions in the traditional society, social mobility in a developing society entails a somewhat different experience from mobility in industrial society entails a somewhat different experience from mobility in industrial society. In the view of Kelsal et. al. (1972) education has become the key element in the process of social 
mobility in today's societies. Educational qualification and the number of years completed at school have also become the most important criteria for occupational attainment. The positive association between years of schooling and level of occupational attainment is, in Kelsal's view, true both of developed and underdeveloped countries.

In the same vein, Parelius and Parelius (1978) in their study of incomes profile in the United States showed that the median income of all whites above eighteen years who are year-round full-time worker was higher if they had four years of college. The association is no less true of Nigeria where according to Aboyade (1973) earnings vary between non-literate primary school leavers, secondary school and university graduates. In the s Nigerian situation, Imoagene (1990) contends that occupational attainment and entry into elite position in the society seem to be dependent more than anything else on credentials.

Other scholars have emphasized on the pattern of stratification in the educational system. For instance, Glick and Miller (1956) argue that limitations to educational attainment in society is brought about because some individuals who have the capacity to acquire more than a modest degree of education do not have the motivation or the means to do so. Also, others lack the mental ability to pursue their education as far as they wish and can afford.

However, it would be reasonable to believe that majority of people who eventually complete their schooling can justifiably expect to receive considerably higher income on entering the labour market. Along this argument, Glick and Miller (1956) demonstrate that there is a progressive increase in the average amount of annual income associated with each increase in education. This is to say that each year invested in schooling can be associated with a monetary return.

The present study seeks to examine the relationship between education and social mobility with particular reference to the situation in Ilorin, capital city of Kwara state, Nigeria.

\section{The Problem}

A number of problems have arisen from the unequal distribution of educational opportunity among people in the Nigerian society. More 
important, education has an overriding effect on the pattern of social mobility within the society. In specific forms, the denial of educational opportunity or rights to some individuals and groups has often led to agitation by these sections of the society. No doubt, educational qualifications are required for ensuring that the right persons fill certain positions in the society. However, the question arises: considering that some individuals do not have access to education, can such a society be said to operate a meritocratic system? Put differently, the unequal access to educational opportunities would also be seen to have overriding consequences on the extent to which a society could fill certain positions that require specialized knowledge or skill acquired chiefly through formal education.

Another important issue especially as it concerns the present study is the implication of education on social mobility in the Nigerian society. Put succinctly, in what ways do educational qualification influence the pattern of social mobility?

These and other related issues constitute the problem which the present study seeks to investigate.

\section{Objectives of Study}

The objectives of the study include to:

- determine the average level of educational attainment of people in our study area i.e. Ilorin metropolis;

- investigate the relationship between educational achievement and social mobility;

- examine other factors i.e. socio-cultural which serve to promote or impede educational achievement among people in the study area; and lastly,

- suggest measures for enhancing positive attitude towards education among the people.

\section{Significance}

The study is considered significant for a number of reasons. Firstly, the study highlights the importance of education to individuals, groups and the entire society. Secondly, it offers explanation into the structure of the Nigerian society with regards to the stratification system especially as it concerns education. 


\section{Methodology}

The study was conducted between the months of March and July, 2006. The field work involved the researcher and two research assistants who helped in administering the questionnaire to the respondents.

The primary research instrument is the questionnaire. It was designed in such a way that it made it possible to obtain wide range of information relating to the educational status and social mobility among the subjects. Essentially, the questions relates to the personal characteristics of the subjects i.e. their age, sex, marital status, religion, ethnic background etc. Other questions concerns issues on subjects' educational attainment and aspirations as well as their pattern of social mobility consequent upon their educational achievement.

The study population comprised of male and female adults resident in Ilorin. This comprise of both indigenes and non-indigenes resident in the town. It is hoped that this enlarged scope of the study population would make it possible for us to obtain contrasting data that would be useful for a wide range of comparisons.

A total of 265 subjects were chosen as sample for the study. The selection was done using a combination of simple random and stratified sampling techniques. To achieve this, the city was grouped into four strata corresponding to the four residential zones in Ilorin namely,

1. the Government Reserved Area (GRA);

2. the old or tyraditional areas comprising of Idi-Ape, Pakata, Omoda, Alore, Okekere, Ita Ogunbo, Oke Aluko, Gambari among others;

3. the modern private layouts or estates e.g. Adewole Estate, Oloje Housing Estate, Irewolede Estate;

4. Urban fringes comprising of emergent settlement within the town e.g. Oko-Erin, Gaa Akanbi, Tanke, Fate etc.

Sixty samples were selected at random from each of the zones except the traditional area where eighty-five (85) were chosen. The inclusion of larger sample from the traditional quarters was meant to enrich the data as residents comprised mainly of indigenes while the population density is higher than the other zones.

On the whole, out of the total of 186 questionnaires that were returned, only 226 were considered valid. This figure (226) therefore shall be the basis of data analysis for the study. 


\section{Hypotheses}

The following hypotheses are proposed to guide the attainment of the study objectives:

1. Respondents' educational attainment is determined by fathers' educational level.

2. Respondents' income is determined by educational achievement.

3. Respondents' Social status is largely determined by educational achievement

\section{Results and Discussions of Findings}

As shown in table 1, respondents' educational distribution reveals that the largest proportion of respondents 26.11 percent are those with Primary education. This is followed by those with no formal education (16.81 per cent) School certificate holders (20.31 percent) First degree graduate (10.18 percent) N.C.E. /OND 14.10 percent and Postgraduate (12.39 percent). This data reflects that on the average, the larger proportion of the respondents in the study area have low education (i.e. those with Secondary School Education and below (63.23 percent) while about 36.67 percent have a relatively higher educational qualification i.e. those with more than Secondary school education.

Table 2 reflects respondents estimate annual income. The finding shows that the largest proportion of respondents are those with an annual income of below N10,000.00k (31.86 percent) followed by those who earn between $\mathrm{N} 10,000.00 \mathrm{k}$ and $\mathrm{N} 40,000.00 \mathrm{k}$ (23.5 per cent). The next proportion is respondents with estimate annual income of between N40, 000.00k and N70, 000.00k (23.45 percent). Only 15.49 percent of respondents earn between N70, 000.00k and N100, 000.00k while about 9.73 percent earn N100, 000.00k and above.

This finding would attest that on the average, the majority of respondents are those with low income. This finding is a reflection of respondents' educational qualification with a larger majority with low educational level.

Table 3 shows respondents fathers' educational level with the largest proportion of respondents (25.67 percent) indicating that their father has no 
formal education followed by those who indicated that their father possess first school leaving certificate (19.91 percent) while 18.58 percent indicated that their father possess school certificate. Only 14.0 percent of the respondents indicated that their father has NCE/OND while 15.97 percent expressed that their father has first degree while 5.31 percent indicated that their father has post graduate certificates.

This finding would show that generally, respondents' fathers have low educational qualification. This finding reflects the intergenerational aspect social mobility in which an individual's social position including educational attainment would be a reflection of parents' status.

Lastly, on the hypotheses tested, the calculations reflect that the null hypotheses which indicate no relationship between parents' education and respondents' educational attainment was accepted. This implies that respondents' educational attainment is not associated with their parents' educational level. This finding confirms Imoagene's (1986) thesis of intergenerational mobility among people in contemporary society in which children of farmers and non-literates have attained higher social placement due to their educational attainment. On the other hand, the null hypotheses of no relationship between respondents' education and income as well as between education and social status were rejected while the alternative hypotheses which suggest close relationship between the variables were accepted. In other words, our finding shows that there is association between respondents' educational level and income on one hand, as well as between their educational attainment and social status.

With this finding, one would conclude that education has an important effect on the level of social mobility among our respondents. As the finding reflects, respondents' movement within the social ladder is a reflection of their educational attainment. For instance, education determines the level of respondents' income and their social status. This finding would seem to agree with Glick and Miller's (1956) assertion that there is a progressive increase in the average amount of annual income associated with each increase in education. That is, educational achievement can be associated with monetary return. The finding also agrees with Imoagene's (1976) assertion that there is positive association between years of schooling and level of occupational attainment and income in most countries. Specifically, that occupational 
attainment and entry into elite positions in the society seem to be dependent, more than anything else, on credentials.

\section{Summary and Conclusion}

The study has focused on the impact of education on social mobility among residents of Ilorin metropolis. It found a close association between respondents' education and level of income as well as between their educational attainment and social status. However, no such association was found between fathers' educational level and respondents' educational attainment.

The import of the finding is that education determines a number of life chances, for instance, income and social status. The study has also demonstrated that a large proportion of people in the study area have low educational status which also affect their income which was found to be relatively low.

Finally, the study has demonstrated that education is a very important determinant of social mobility, especially in developing countries. Therefore efforts meant to improve on the life chances of the people must necessarily involve an improvement in their educational attainment. 


\section{References}

Aboyade, O. (1983) Income profile (Unibadan Inaugural Lectures) Ibadan: Ibadan University Press.

Akerejola, G. (1977) The Relationship of Social Mobility and Schooling, Zaria: Ahmadu Bello University, Department of Education.

Bilton, T. et. al. (1989) Introductory Sociology, London: Macmillan. Davis, K. and Moore, W. (1945) "Some principles of stratification" American Sociological Review, 10: 242-249.

Dubey, D.L. Edem, D. A. and Thakur A.S. (1984) An Introduction to the Sociology of Nigerian Education, London: Macmillan Press.

Giddens, A. and Duneier, M. (2000) Introduction to Sociology, New York: W.W. Norton and Company.

Glick, P. C. and Miller, H. (1956) Educational Level and Potential Income" American Sociological Review, 21: 307-312.

Haralambos, M. and Holborn, M. (2000) Sociology: Themes and Perspectives,London: HarperCollins Publishers Limited.

Imoagene, O. (1976) Social Mobility in Emergent Society: A Study of the New Elite in Western Nigeria, Camberra: Australian National University.

Imoagene, O. (1990) Predicting Success in a Developing Society, Unibadan Inaugural Lectures, Ibadan: Ibadan University Press.

Kelsall, R. K. et. al. (1972) Graduate: The Sociology of an Elite, London: Tavistock Publishers.

Marsh, I. (1997) Making Sense of Society: An Introduction to Sociology, London: Addison Wesley Longman Ltd.

Marx, K. and Engels, F. (1954) The Communist Manifesto, Chicago: Regnery.

Parelius, A. P. and Parelius, R. Y. (1978) The Sociology of Education, Englewood Cliffs: N.Y. Prentice Hall Inc.

Schaefer, R.T. (1989) Sociology, New York: McGraw-Hill Inc. 
Table 1: Distribution of Respondents' Educational Qualification

Education level

No Formal Education

16.81

Primary School

26.11

Secondary

20.35

NCE/OND

14.16

HND/B.Sc.

10.18

Post graduate

12.39

Total

28

$226 \quad 100$

Table 2: Respondents'Income level

\begin{tabular}{llcr} 
Income Level (Monthly Estimate) & No & \multicolumn{1}{c}{$\%$} \\
\hline Below N10,000 & 72 & 31.86 \\
Between & $\mathrm{N} 10,000$ and N40,000 & 53 & 23.45 \\
Between & $\mathrm{N} 40,000$ and N70,000 & 44 & 19.47 \\
Between & N70,000 and N100,000 & 35 & 15.49 \\
N100,000 \& above & 22 & 9.73 \\
\hline Total & $\mathbf{2 2 6}$ & $\mathbf{1 0 0}$
\end{tabular}

Table 3: Father's Educational Level

\begin{tabular}{lcc} 
Father's Education & No & $\%$ \\
\hline No formal education & 58 & 25.67 \\
First school leaving certificate & 45 & 19.91 \\
School certificate & 42 & 18.58 \\
NCE/OND & 33 & 14.60 \\
First degree /HND & 36 & 15.93 \\
Post graduate & 12 & 5.31 \\
Total & 226 & 100 \\
\hline
\end{tabular}

Table 4: Relationship between Parents' Education and Respondents' Educational Attainment

Respondents' Education

$\begin{array}{lllrr}\text { High } & 5 & 19 & 27 & 51 \\ \text { Moderate } & 7 & 37 & 34 & 78 \\ \text { Low } & 8 & 28 & 61 & 97 \\ \text { Total } & 20 & 84 & 122 & 226\end{array}$

$\mathrm{N}=226 ; \mathrm{X}^{2}=7.11 ; \quad$ D.F. $=9 ; \quad \mathrm{X}^{2} 0.05=16.92 ; \quad \mathrm{H}^{0}$ is Accepted

(See Appendix A for computation of tested hypothesis) 
Table 5: Relationship between Respondents' Educational Level and Income

\begin{tabular}{lrrrr}
\multicolumn{3}{c}{ Respondents' Educational Level } & \multicolumn{3}{c}{ Respondents' Inco } \\
\cline { 2 - 5 } High & Moderate & Low & Total \\
High & 12 & 21 & 18 & 51 \\
Moderate & 6 & 24 & 48 & 78 \\
Low & 4 & 34 & 59 & 97 \\
\hline Total & 22 & 79 & 125 & 226 \\
\hline
\end{tabular}

$\mathrm{N}=226 ; \mathrm{X}^{2}=19.39 ; \quad$ d.f. $=9 ; \mathrm{X}^{2} \quad 0.05=16.92 ; \mathrm{H}^{0}$ is Rejected

(See Appendix B for the computation of tested hypothesis)

Table 6: Relationship between Respondents' Educational Attainment and Social Status

Respondents' Educational Level

\begin{tabular}{lcccc} 
& \multicolumn{4}{c}{ Respondents' Social Status } \\
High & Upper & Middle & Lower & Total \\
Moderate & 32 & 09 & 06 & 51 \\
Low & 38 & 30 & 36 & 78 \\
Total & 12 & 49 & 56 & 97 \\
& 57 & 71 & 98 & 226
\end{tabular}

$\mathrm{N}=226 ; \mathrm{X} 2=84.24 ; \mathrm{df}=9 ; \mathrm{X} 2 \quad 0.05=16.92 ; \mathrm{H} 0$ is Rejected.

(See Appendix C for computation of tested hypothesis)

\section{APPENDIX: CHI-SQUARE $\left(\mathrm{X}^{2}\right)$ STATISTICAL COMPUTATION}

Chi-Square formula: $\mathrm{X}^{2}=\Sigma \underline{(\mathrm{O}-\mathrm{E})}$

where, $\quad \Sigma=$ sum of

$$
\begin{aligned}
& \mathrm{F}=\text { Frequency } \\
& \mathrm{O}=\text { Observed frequencies } \\
& \mathrm{E}=\text { Expected frequencies }
\end{aligned}
$$




\section{APPENDIX A: COMPUTATION OF HYPOTHESIS 1}

\section{Statement of Hypothesis:}

Respondents' educational attainment is determined by their fathers' educational level

Null Hypothesis $\left(\mathrm{H}^{0}\right)$ : There is no relationship between Parent's education and respondents' educational attainment.

Alternative hypothesis $\left(\mathrm{H}^{1}\right)$ : There is a relationship between Parent's education and respondents' educational attainment.

2

FO $\quad$ FE $\quad($ FO - FE $)$ FE

\begin{tabular}{|c|c|c|}
\hline 5 & 4.5 & .05 \\
\hline 19 & 18.9 & .005 \\
\hline 27 & 27.5 & .009. \\
\hline 07 & 6.9 & .001 \\
\hline 37 & 28.9 & 2.27 \\
\hline 34 & 42.1 & 1.6 \\
\hline 08 & 8.5 & .03 \\
\hline 28 & 36.0 & 1.7 \\
\hline$\underline{61}$ & 52.3 & 1.44 \\
\hline 226 & & 2 \\
\hline
\end{tabular}

APPENDIX B: CHI-SQUARE STATISTICAL COMPUTATION OF HYPOTHESIS 2

Statement of Hypothesis: Respondents' income is determined by their educational achievement.

Null Hypothesis $\left(\mathrm{H}^{0}\right)$ : There is no relationship between Respondents' educational achievement and their income.

Alternative hypothesis $(\mathrm{H})$ : There is a relationship between Respondents' educational achievement and their income. 


\begin{tabular}{rrc} 
FO & FE & $($ FO - FE $) \mathrm{FE}$ \\
12 & 4.9 & 10.28 \\
21 & 17.8 & 0.57 \\
18 & 28.2 & 3.68 \\
6 & 7.5 & 0.3 \\
24 & 27.2 & 0.37 \\
48 & 43.1 & 0.55 \\
4 & 9.4 & 3.1 \\
34 & 33.9 & 0.0002 \\
59 & 53.6 & 0.54 \\
\hline 226 & $\Sigma \underline{(\mathrm{O}-\mathrm{E})}=19.39$ \\
& $\mathrm{E}$
\end{tabular}

\section{APPENDIX C: CHI-SQUARE STATISTICAL COMPUTATION OF HYPOTHESIS 3}

Statement of Hypothesis: Respondents' Social status is largely determined by their educational achievement

Null Hypothesis $\left(\mathrm{H}^{0}\right)$ : There is no association between Respondents' educational achievement and social status.

Alternative Hypothesis $\left(\mathrm{H}^{1}\right)$ : There is an association between Respondents' educational achievement and social status.

\begin{tabular}{|c|c|c|}
\hline FO & FE & $(\mathrm{FO}-\mathrm{FE}) \mathrm{FE}$ \\
\hline 32 & 12.8 & 28.8 \\
\hline 09 & 16.0 & 3.0 \\
\hline 06 & 22.1 & 11.7 \\
\hline 38 & 19.6 & 17.2 \\
\hline 30 & 24.5 & 1.2 \\
\hline 36 & 33.8 & 0.14 \\
\hline 12 & 24.4 & 6.3 \\
\hline 49 & 30.4 & 11.3 \\
\hline 56 & 42.0 & 4.6 \\
\hline 226 & & 2 \\
\hline
\end{tabular}

